\title{
O SMARTPHONE NA SALA DE AULA DE LÍNGUA INGLESA: INTEGRANDO ARTEFATO E TAREFAS PELA ABORDAGEM DA TEORIA ATOR-REDE1
}

\section{THE SMARTPHONE IN THE ENGLISH \\ CLASSROOM: INTEGRATING ARTIFACT \\ AND TASKS BY ACTOR-NETWORK \\ THEORY APPROACH}

KHATCHADOURIAN, Luana de França Perondi

Doutoranda em Linguística Aplicada - IEL UNICAMP

E-mail: luanaperondi@gmail.com

ORCID ID: http://orcid.org/0000-0002-4104-0178

\section{RESUMO:}

O presente artigo é parte uma pesquisa de doutorado em linguística aplicada cujo objeto é o uso do aparelho celular do tipo smartphone na sala de aula de lingua inglesa em escolas públicas de periferia. O uso do aparelho celular em sala de aula já foi proibido e hoje é liberado para uso pedagógico. Mas o que seria, de fato, uso pedagógico? Liberar tal artefato no contexto escolar pressupõe dizer como ele deve ser apropriado? Com base na teoria ator-rede de Bruno Latour e colegas, este trabalho defende a tese de que o aparelho celular precisa ser tratado como um elemento mediador inserido em toda uma rede de agências e agentes que constitui o que chamamos de aula, e que o efeito da sua entrada na sala de aula depende das diferentes relações entre atores humanos e não-humanos que já ocorrem nessa rede. Toma-se por hipótese que usando-se a aprendizagem baseada em tarefas e mobile language assisted learning é possível integrar o aparelho ao fluxo do ensino-aprendizagem sem descaracterizar excessivamente o potencial desse artefato na vida real, e, ao mesmo tempo, mantendo-se a sala de aula produtiva, gerando aprendizagem, mesmo que de forma diferente da tradicional.

$\overline{1}$ O presente trabalho foi realizado com apoio da Coordenação de Aperfeiçoamento de Pessoal de Nível Superior - Brasil (CAPES) - Código de Financiamento 001 
Palavras-chave: Smartphones; Teoria Ator-Rede; Mobile Assisted Language Learning.

\section{ABSTRACT:}

This paper is a partial result of a doctoral research in applied linguistics, where the object is the use of smartphones in English classes at public schools from underprivileged regions. Indeed, the use of the cell phone in the classroom has already been banned, however it can be used with educational purposes. Then, it emerges the question what would be a pedagogical use? To admit this gadget in the school context presupposes stablishing how it could be appropriately used? Therefore, supported by the actor-network theory, postulated by Bruno Latour and colleagues, this paper argues that the smartphone should be seen as a mediator tool, that is inserted in a network of agencies and agents that constitutes what we call class, and that the effect of the entrance into the classroom should rely on the different relationships between human and nonhuman actors that have been already occurring in this network. The hypothesis is that using task-based and mobile language assisted learning it is possible to integrate the device into the teachinglearning flow without overcharging the potential of this artifact in real life, and meanwhile, the classroom becomes a productive environment, that generates learning, even if it is in a way distinct from the traditional one.

Keywords: Smartphones; Actor-Network Theory; Mobile Assisted Language Learning.

\section{INTRODUÇÃO}

Este trabalho é parte de minha pesquisa de doutorado sobre o uso do aparelho celular do tipo smartphone nas aulas de inglês no ensino público, realizada em escola localizada na periferia da cidade de São Paulo, que atende os alunos de uma das maiores favelas da região leste da cidade. A escola a foi escolhida por ser classificada entre as piores no nível do IDESP (Índice de Desenvolvimento da Educação do Estado de São Paulo), indicador criado em 2007 pela Secretaria de Educação de São Paulo para avaliar a qualidade das escolas da rede. Nessa avaliação, considera-se que uma boa escola é aquela cuja maior parte dos alunos apreende as competências e habilidades requeridas para a sua série. 
Minha pesquisa é caracterizada como uma pesquisa-ação, no sentido de que pretendo, com ela, promover uma intervenção, protagonizada pela comunidade, voltada para melhorar a aprendizagem de língua estrangeira com a ajuda de novas tecnologias. A metodologia de pesquisa utilizada envolve observações de aula e encontros periódicos com a professora responsável pelas aulas de inglês da sala em que faço observações, o planejamento conjunto de atividades e materiais didáticos para serem aplicados com o uso do aparelho celular na aula de inglês.

A despeito do uso social generalizado do aparelho celular, foi sancionada em 2007 a Lei $n^{\mathbf{0}}$ 12.730, de autoria do deputado Orlando Morando, a qual veta o uso do aparelho nos estabelecimentos de ensino do Estado de São Paulo, durante o horário de aula. Segundo o deputado, a proibição celular em sala de aula é necessária e se harmoniza com o ambiente em que o estudante está. Morando assegura que ter acesso fácil ao celular faz com o que aluno tenha mais chances de distração, o que pode levar a notas mais baixas; que adolescentes ainda não têm maturidade para usá-lo nos momentos apropriados -- em ambientes liberados, é muito difícil para o professor monitorar a sala toda--; e a distração do smartphone é, para o Deputado, muito pior do que desenhar no caderno, por exemplo, porque o aluno entra em um 'universo paralelo'. ${ }^{2}$

De outro lado, professores conscientes do potencial do uso de novas tecnologias como ferramentas pedagógicas reconhecem que o uso dos celulares em sala de aula deve ser incentivado servindo como ferramenta útil ao processo de aprendizagem. A favor destes que acreditam que o uso do celular em sala de aula pode ajudar no processo ensino aprendizagem, o governador de São Paulo Geraldo Alckmin sancionou, no dia 06 de novembro de 2017, Projeto de Lei 860/2016, que autoriza o uso de telefones celulares para fins pedagógicos em salas de aula.

A presente pesquisa iniciou-se no momento em que a proibição ainda vigorava, porém ao final da geração de dados a ocorreu a liberação. Mesmo com tal decreto, nota-se que não foram e - diga-se de passagem - ainda não são claros quais os critérios que dizem qual o tipo de uso é pedagógico e qual não é.

Em um estudo piloto, tive a oportunidade de observar algumas aulas de uma professora de inglês no ensino médio de uma escola

$\overline{2}$ ASSEMBLEIA LEGISLATIVA DO ESTADO DE SÃO PAULO. Opinião - Celular em sala de aula: uma proibição necessária. Disponível em: https://www.al.sp.gov.br/noticia/?id=365340> Acesso em 10.04.2018. 
estadual da periferia na cidade de São Paulo e observei que os alunos usavam smartphone em aula para uma série de coisas que pouco ou nada têm a ver com ensino-aprendizagem de língua estrangeira. Ações como escutar música com fones de ouvido, tirar foto da lousa em vez de copiar, conversas por meio de redes sociais, jogos online, afastamento espacial do centro da aula (sempre nos cantos e nos fundos da sala) demonstram como o artefato pode de fato desorganizar a rede de ações coordenadas que fazem acontecer o que chamamos de aula.

Tais observações reforçam a tese de que o uso do artefato afeta a dinâmica da sala de aula, sem que seu potencial educacional, seja lá como seja definido, seja, em nenhum momento, canalizado para o processo de ensino-aprendizagem em si.

Quando esta pesquisa se refere ao potencial do smartphone no processo de ensino-aprendizagem, tem-se em mente a sua capacidade de permitir que haja participação, colaboração, experimentação, hibridização de linguagens entre outras características da cultural digital que deveriam ser a base das inovações educacionais baseadas em tecnologias digitais da informação e comunicação (BUZATO, 2010). Usos pedagógicos que reproduzam práticas prévias à cultura digital, portanto, são vistas como práticas que descaracterizam o artefato em seu verdadeiro potencial.

Pensar sobre a permanência e o papel desempenhado pelo smartphone na sala de aula é uma maneira de tentar aproximar as práticas de aprender institucionalizadas e estabilizadas da escola com as formas de aprendizagem informal e baseada em circulação-cooperaçãocolaboração engendradas pela cultura digital.

A experiência de ensino-aprendizagem em sala de aula nas escolas públicas é hoje - ou deve ser - bastante diversa daquela com que nos acostumamos ao longo da nossa experiência discente. No que tange ao ensino de língua inglesa, ela deveria ter mudado mais significativamente por conta das várias influências culturais e tecnológicas com as quais hoje os alunos têm contato mais fácil e mais frequente do que era possível no passado.

A prática de ensino de inglês na escola, porém, pode ser descrita como estabilizada. Isso está, certamente, em correlação com a estabilização da rede de artefatos e atividades que constituem a aula. Diferentemente do caso do uso de tecnologias mais antigas como a lousa, a carteira, o livro didático, ou mesmo o vídeo e o aparelho de áudio, no caso do smartphone, ainda não se encontrou uma maneira 
de vinculá-lo ao processo, o melhor, a essa rede de agentes/artefatos que constituem a aula, sem desetabilizar as relações entre o professor, o aluno, tempo, espaço e aprendizagem, como ilustram os exemplos do estudo piloto já mencionados.

Uma forma de compreender essas relações, com vistas a traçar estratégias didáticas do uso de smartphones na sala de aula que permitam utilizar o potencial verdadeiro do aparelho, sem desconstruir completamente o processo de ensino-aprendizagem tal como tradicionalmente se desenvolve nas salas de aula, é justamente pensar o problema a partir de uma perspectiva de rede. Dito de outra forma, trata-se de pensar a sala de aula como uma rede de atores que são eles mesmos redes em potencial, nos moldes da Teoria Ator-Rede de Bruno Latour (2005).

Para Latour, qualquer evento ou prática social se estabelece a partir de vínculos entre elementos humanos e não-humanos que constituem uma rede cuja configuração pode mudar as identidades e competências de cada membro. Por exemplo, se os alunos usam celulares em aula, o caderno pode deixar de ser um ator que "copia matéria" para levar para casa, já que o celular passa a ser utilizado para fotografar a lousa e guardar o registro na nuvem, e pode, por exemplo, passar a ser um ator que guarda anotações sobre aquilo que foi fotografado, talvez "metadados" (quando, qual o assunto, vai cair na prova?, "círculos são verbos, quadrados substantivos" por exemplo). O professor que confiava em que a cópia da lousa era uma forma efetiva de aprender perde essa forma de vincular o ensino à aprendizagem, sendo necessário integrar a foto da lousa, de alguma maneira, às atividades que propõe, caso contrário também o tempo que passa na lousa perde seu valor didático: a lousa passa a ser aquilo que distrai e faz o tempo passar, mas não gera aprendizagem (papel que, antes, nos exemplos citados, era do celular).

Partindo desta ótica relacional, baseada em Latour (2005), e da concepção de inovação educacional baseada em TDIC (tecnologias digitais de informação e comunicação) proposta por Buzato (2010), pode-se expressar o problema a que remete esta pesquisa com a seguinte pergunta: como integrar o smartphone de forma produtiva na sala de aula sem mutilar o artefato em suas possibilidades de inovação educacional?

Como pressuposto para responder essa pergunta, assumo que a participação efetiva do smartphone, com seu potencial integral, na rede de artefatos e pessoas que constituem a dinâmica da sala de aula, provocará desvios e desestabilizações dos papéis e métodos ali 
estabelecidos tradicionalmente, os quais tanto podem ser disruptivos quanto efetivamente produtivos no sentido da promoção da aprendizagem de língua inglesa. Minha hipótese é a de que as tarefas propostas pelo professor, dependendo de como são construídas, e a partir de que base teórica, podem ser um ator chave nessa rede, capaz de mediar e tornar produtiva a multiplicidade de linhas de ação estabilizadora e desestabilizadora trazida pelo smartphone.

\section{FUNDAMENTAÇÃO TEÓRICA}

Muitas teorias que reconhecem o papel mediador dos artefatos (nesse caso, o smartphone) na aprendizagem, como é o caso, exemplarmente, a Teoria Sociocultural da Aprendizagem (VYGOSTSKY, 1978,1994, 2000). De acordo com essa teoria, a aprendizagem é afetada e modificada pelas ferramentas utilizadas para ela e, reciprocamente, as ferramentas de aprendizagem são modificadas pela forma como são utilizadas.

O uso de dispositivos móveis pode afetar drasticamente o tempo, o local e os meios de interação do processo de aprendizado. Embora os dispositivos móveis removam algumas restrições, eles apresentam outros desafios. Em essência, o aprendizado móvel pode representar um novo paradigma na educação. (KOOLE, 2006, p.14)

Neste caso, porém, é preciso reconhecer que o smartphone não é um artefato comum, sobretudo porque ele apresenta, ao mesmo tempo, a possibilidade de simular, representar, registrar e processar conteúdos e de mobilizar, ou fazer circularem, conteúdos, conversas, dúvidas e discussões coletivamente e à distância de forma síncrona. É necessário, portanto, buscar-se apoio teórico, nesse sentido, no campo da Aprendizagem de Linguas Assistida por celular ou Mobile Assisted Language Learning (TRAXLER, 2013; KUKULSKA-HULME, 2013; STOCKWELL e HUBBARD, 2013)

No caso do ensino de línguas, é importante considerar que todo esse potencial só vai ser útil se houver a mediação de tarefas que permitam organizar e encadear esses diferentes potenciais visando a aprendizagem, ao mesmo tempo em que se descentraliza o ensino da figura do professor e mesmo do espaço físico da sala de aula (WILLIS, 1996; NUNAN, 2004; WILLIS e WILLIS, 2007)

Finalmente, para entender a relação entre o artefato, as tarefas, o professor e os alunos, no processo de ensino-aprendizagem, é preciso 
recorrer a uma teoria que permita ressaltar a agência do próprio artefato, o celular, em relação à agência dos elementos humanos envolvidos, ou seja, o professor e os alunos, especialmente no campo da educação (ROTH e MCGINN, 1997; NESPOR, 2002; LATOUR, 2005; BUZATO, 2010; FENWICK e EDWARDS, 2010). Esse é o papel da Teoria Ator-Rede (LATOUR, 2005).

MALL - Mobile Assisted Language Learning

Um primeiro passo para postular uma teoria da aprendizagem móvel - Mobile learning (doravate m-learning) - é distinguir o que é especial sobre ela em comparação a outros tipos de aprendizagem. A primeira diferença essencial é que ela parte do pressuposto de que os alunos estão continuamente em movimento, aprendendo por meio do espaço - apropriando-se de ideias e fontes obtidas em um local com a possibilidade de aplicá-las ou desenvolvê-las em outro (SHARPLES et al., 2009,). Isso inclui, em tese, usar o celular, em sala de aula, para aprender algo sobre outro assunto acadêmico, considerado prioritário ou mais interessante.

O m-learning é a capacidade de ocorrência do processo de ensinoaprendizagem por meio das diversificadas plataformas móveis, tais como o tablet ou o smartphone, além de outras menos convencionais -- como um pocket PC, por exemplo -, que se baseiam na conectividade sem fio para permitir que haja comunicação entre aprendiz e educador e cuja finalidade seja interação que vise a um processo de ensino-aprendizagem (COLL e MONEREO, 2008, p. 45).

Em vista do objeto específico da pesquisa, tomo como referência um tipo específico de aprendizagem móvel, sugerido pela sigla MALL Mobile-Assisted Language Learning (Aprendizagem de línguas assistida por dispositivos móveis - doravante MALL). A MALL descreve, portanto, a aprendizagem de línguas, assistida ou melhorada por meio do uso de um dispositivo móvel portátil (TRAXLER, 2013; STOCKWELL e HUBBARD, 2013).

Vale ressaltar que a MALL pressupõe que aprendizagem é mais do que conteúdo, é um conjunto de "experiências" e, logo, proporciona condições de pensar como o uso do smartphone pode afetar ou trazer experiências na sala de aula, em vez de ser usado apenas como uma forma de acesso ao repositório de conteúdos ou uma forma de registro ou gravação de conteúdos.

E ainda com o MALL surge a consciência de que os aparelhos móveis permitem o cruzamento de 
fronteiras entre aprendizagem formal dentro da sala de aula e aprendizagem informal fora da sala de aula (KUKULSKAKHULME, 2009, p.127).

Após ter realizado levantamento bibliográfico dos principais trabalhos na área nos últimos 15 anos, observei que publicações internacionais como as de Stockwell e Liu (2015); Sharples et al. (2005, 2007, 2009); Poll (2014); Stoller-Schai (2015); Cochrane e Bateman (2010); e Mohammad et al. (2015), dizem respeito a retirar a aprendizagem da escola, mobilizando-a, e não, como no presente caso, trazê-la para dentro da sala de aula utilizando aparelhos móveis - mais especificamente o smartphone, como eu proponho.

No processo de pesquisa, nota-se nitidamente, também, uma lacuna nos estudos de m-learning e de MALL. Em geral, os trabalhos se concentram em discorrer sobre a forma como o aluno aprende em diversos momentos e espaços por meio de aparelhos móveis — o que é natural —, mas não vão além a ponto de pensar, de fato, uma integração do smartphone como os demais atores do processo educacional no espaço escolar. Atribuo essa lacuna, em parte, à falta de uma discussão mais aprofundada sobre o que seriam tarefas apropriadas para MALL, isto é, tarefas que efetivamente utilizassem os potenciais do celular para criar-se experiências, além de conteúdos, experiências essas que integrem os atores humanos e não humanos de forma produtiva no sentido da aprendizagem.

Baseada em minha experiência de campo na escola onde venho desenvolvendo a pesquisa, posso afirmar de que este tipo de dispositivo, neste espaço, tem servido para, simbolicamente, deslocar os alunos, transferindo-os do espaço da sala de aula para outros, embora esta transferência simbólica de espaço e de contexto não esteja servindo para a aprendizagem.

Assim, percebe-se que o smartphone pode simplesmente "desconfigurar" completamente a sala de aula enquanto contexto de aprendizagem, sendo essa, obviamente, uma das razões da sua proibição no passado. Resta saber se essa mesma agência do smartphone pode ser canalizada e disciplinada, sem mutilação do seu potencial, para "reconfigurar" a sala de aula de forma produtiva, no sentido da promoção da aprendizagem. Isso terá a ver, certamente, com o tipo de relação estabelecida entre o celular, o professor, os alunos, os materiais, as demais tecnologias e, especialmente, as tarefas.

\section{A TEORIA ATOR-REDE}

A Teoria Ator-Rede (doravante TAR) é uma abordagem empíricofilosófica que permite estudar as tecnologias como um conjunto de 
mediações reunindo pessoas e coisas ou atores humanos e não-humanos numa assemblage que gera efeitos reais em determinado lugar ou situação. (LATOUR 2005, p. 105)

De acordo com os teóricos da TAR (LATOUR, 2005; LEE e BROWN, 1994; LAW e HASSARD, 1999, entre outros), a sociedade não é uma estrutura, mas um efeito que se produze como redes que rastreiam relações dentro de si mesmas, sendo continuamente reconstituídas como são ou sujeitas à reformulação e à transformação a depender dos elementos que ali venham a se agregar, ou que venham a se desvincular da rede constituída.

Não se trabalha com a noção de estrutura social, tudo passa ser agência e performance, tanto humanos como não humanos agem e tais ações configuradas em rede é que criam a sensação de estrutura ou permanência das instituições e das práticas sociais. Os objetos têm agência, o que significa "estar associado de tal modo que fazem outros atores fazerem coisas" (LATOUR, 2005, p. 52). O humano não é vítima do processo, mas não se pode afirmar que seja um protagonista autônomo em ação.

A TAR propõe que se desfaça qualquer tipo de determinismo, seja de ordem social ou técnica, através do que seria um equilíbrio entre forças humanas e não-humanas buscando, assim, uma outra maneira de se compreender o social, não mais de forma segmentada, mas sim por meio do movimento e das associações que se estabelecem entre elementos heterogêneos presentes em uma rede de relações.

O alcance e a relevância de se utilizar este recorte epistemológicometodológico para estudar uma questão específica da educação é que a partir da lógica em rede - uma das principais premissas da TAR, Latour (2005, p. 64) redefine a noção de social salientando que o

$$
\begin{aligned}
& \text { fundamental é olharmos os engendramentos coletivos e } \\
& \text { não os atores separadamente, pois o material e o social são } \\
& \text { produzidos conjuntamente. Não há como negar a inter- } \\
& \text { relação entre os atores, pois as coisas podem autorizar, } \\
& \text { permitir, sugerir, influenciar, proibir e assim por diante, } \\
& \text { afetando as escolhas e possibilidades dos outros atores. }
\end{aligned}
$$

Por exemplo, para que uma sala de aula funcione, é preciso haver paredes, portas, janelas, luzes, mesas e cadeiras, sem as quais, a qualquer momento, o lugar/atividade sala de aula pode virar outra coisa. Da mesma forma, se, por exemplo, o professor traz para a sala de aula um videoclipe do artista favorito dos alunos em que o vocabulário 
aprendido está sendo utilizado, possivelmente a sala de aula enquanto lugar/atividade seja reforçada, ainda que o ator trazido de fora (videoclipe) não seja tipicamente dali.

A TAR não foi concebida para a pesquisa em educação, mas, uma vez que trata de instituições em geral, e é especialmente útil para o estudo de inovações tecnocientíficas e socias, muitos educadores dela se apropriaram para realizar suas pesquisas. Jan Nespor $(1994,2002)$ foi um dos primeiros pesquisadores educacionais a empregar leitura de redes associadas à TAR para analisar processos educacionais. Ele mostrou, por exemplo, como currículos escritos, vídeos, ações humanas e edifícios podem mover as práticas educativas no espaço e no tempo de modo a produzir o que chamamos de um curso universitário (NESPOR, 2002).

Roth e McGinn (1997, p.24), por sua vez, dizem que a

TAR pode ajudar professores e alunos a desconstruirem sistemas de conhecimento monolíticos por meio do exame das conexões entre coisas e pessoas. A TAR elimina as aparentes "caixas pretas" de muitos conhecimentos curriculares e práticas educativas e oferece recursos para rastrear as muitas redes neles incorporadas.

Os Estudos de m-learning e MALL salientam que o aluno é que circula, não o artefato - circulação dos corpos no espaco geográfico -; no entanto, a TAR permite pensar na circulação das ações à distância, ou seja, enquanto MALL discorre sobre como o corpo que circula no espaço pode trazer conhecimento para um aula, a TAR permite pensar sobre como ações e conhecimento constituídos em outros lugares podem circular para e na sala de aula, sem que o aluno tenha que se deslocar fisicamente, ou mentalmente, no espaço.

Teorias de MALL demonstram que a aprendizagem pode acontecer a qualquer hora em qualquer lugar; a TAR fundamenta o pressuposto de que existem várias aprendizagens, várias vozes, pontos de vista, insumos e interlocutores que passam a poder participar da aprendizagem que acontece, ou falha em acontecer, em sala de aula.

O olhar específico da TAR na contribuição para a adequação do smartphone nas dinâmicas de MALL é que uma análise baseada na TAR parte do pressuposto de "iluminar os processos, ao invés de explicar os resultados finais" (FOX, 2005 p. 102). Nesta pesquisa, o objetivo principal 
é elucidar como a rede chamada "sala de aula", em que o aparelho móvel de smartphone está começando a atuar, se expande e estabiliza ou se desestabiliza e eventualmente desfaz, e como a inserção de um elemento pedagógico específico, qual seja, a tarefa, pode influir no processo e nos efeitos gerados, mais especificamente, o efeito almejado na sala de aula, que é a aprendizagem.

\section{TASK-BASED LEARNING}

A definição mais comumente utilizada de tarefa é a de atividade na qual existe foco no significado. Uma atividade de TBL é aqui definida como uma tarefa pedagógica, uma parte da (sala de) aula na qual existe um trabalho que envolve os alunos produzindo ou interagindo na língua-alvo, enquanto a sua atenção se concentra em mobilizar seus conhecimentos linguísticos, a fim de expressar o significado, e em que a intenção é a de transmitir significado, tendo um senso de completude (NUNAN, 2004).

Nunan (2004, p.12) salienta que a abordagem por tarefas pedagógicas segue os seguintes princípios e práticas:

- Uma ênfase em aprender a se comunicar por meio da interação na língua-alvo;

- A introdução de textos autênticos para a situação de aprendizagem;

- A oferta de oportunidades para os alunos a se concentrarem não só na linguagem mas também no próprio processo de aprendizagem;

- Um aumento das próprias experiências pessoais do aluno como importante contribuição para a aprendizagem em sala de aula; e

Willis e Willis (2007, p.70) salientam que uma boa tarefa não só gera interesse e cria um grau aceitável de desafio, mas também gera oportunidades para os alunos experimentarem e ativarem o idioma tanto quanto seja possível.

Willis (1996) produziu um quadro prático detalhado para uma sala de aula baseada em tarefas nas quais os alunos são levados por ciclos de planejamento de tarefas. São três fases que compõem o sistema do TBL, segundo Willis (1996): pré-tarefa; ciclo da tarefa; e foco na linguagem, tal como a figura abaixo demonstra: 


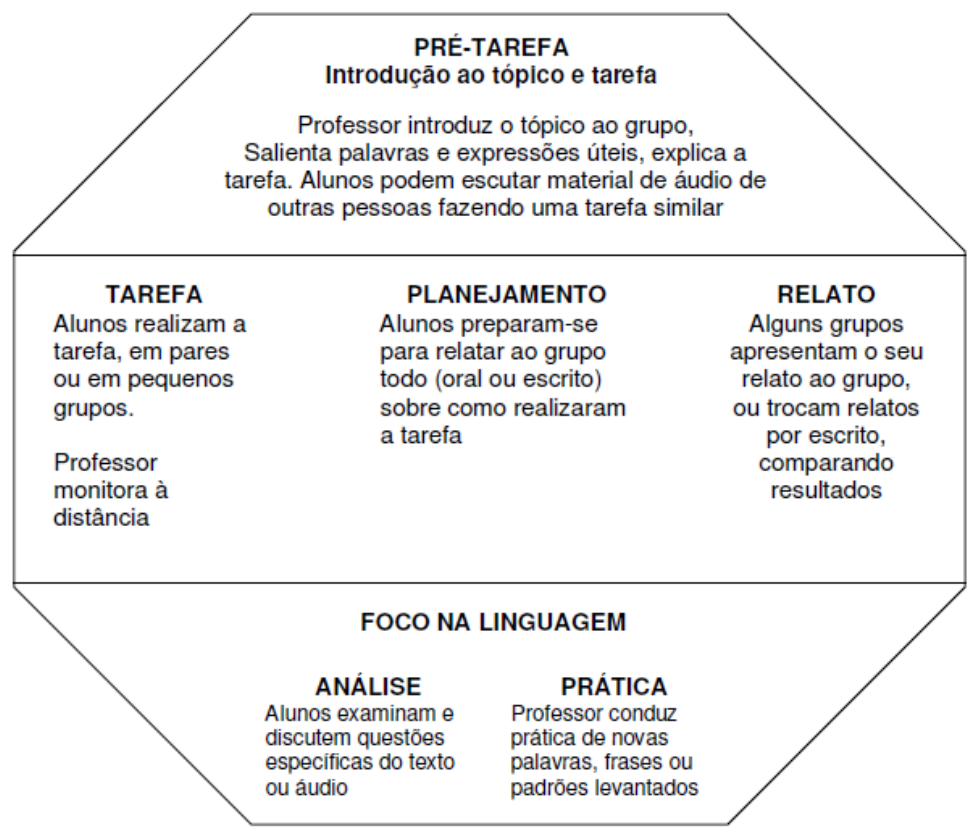

Figura 1: Componentes do esquema de trabalho TBL (WILLIS, 1996 p. 38).

A noção de tarefa é mais próxima da de "experiência" do que de "conteúdo" e, por essa razão, busquei apelar para a TBL e sua estreita associação com o ensino-aprendizagem de língua estrangeira. Aqui, também faço uma relação com MALL que parte, igualmente, do pressuposto que aprendizagem conjunto de "experiências".

A articulação entre MALL, TAR e TBL no presente trabalho pode ser expressa da seguinte forma: o celular, enquanto ator da rede que constituo o lugar/atividade sala de aula tanto pode trazer elementos e experiencias pertinentes para a aprendizagem como levar a atenção dos alunos e a negociação dos seus significados para outros lugares/atividades (m-learning/MALL). Para agregar o celular 'a rede que constitui a sala de aula enquanto lugar e atividade, de modo que ele ajude a sustentar e expandir o processo que traz ao mundo a aprendizagem (TAR), é preciso encontrar atores mediadores que disciplinem as diversas potencialidades do celular numa direção produtiva, sem, contudo, descaracterizar o artefato em sua identidade e sua agência. Minha hipótese é que esses atores mediadores podem ser certos tipos de tarefas (TBL). 


\section{METODOLOGIA - PESQUISA-AÇÃO}

Para dar conta do trabalho ora proposto, optei por realizar uma pesquisa-ação tal qual concebida por Nunan $(1990,2002)$ e Elliott (1991). Como o próprio nome aponta, neste tipo de pesquisa existe uma ação por parte dos pesquisadores, que mereça investigação para ser elaborada e conduzida. Assim, os pesquisadores têm papel ativo no equacionamento dos problemas encontrados, no acompanhamento e avaliação das ações, organizando a própria ação, visando mudar uma situação indesejável. Para os autores, o objetivo principal é a investigação que aponta caminhos para a mudança da prática em sala de aula, permitindo assim um trabalho colaborativo e interligado entre professores e alunos e pesquisadora.

Numa pesquisa-ação, o engajamento dos participantes faz-se necessário por ser uma ação coletiva e colaborativa que estimula o aprofundamento da compreensão e a interpretação de sua própria prática, com vistas ao seu fortalecimento e emancipação. No caso do presente trabalho, a pesquisa-ação se traduz em melhorar a prática de ensino aprendizagem de língua estrangeira no sentido de prover subsídios para o uso do smartphone no ensino de língua estrangeira em escola pública.

\section{Participantes}

Os participantes são os alunos de uma sala do terceiro ensino médio de uma escola estadual da cidade de São Paulo, a professora de inglês responsável pela sala e a esta pesquisadora. Trata-se de uma escola localizada na periferia da cidade de São Paulo, que atende os alunos de uma das maiores comunidades ou favelas da região leste da cidade. Em minhas primeiras observações de aulas, esses alunos permaneceram em sala de aula, em sua maioria, na maior parte do tempo, com seus aparelhos de smartphones ligados, utilizando-os para jogar, ouvir músicas, navegar em redes sociais e tirar fotos da lousa para depois fazer a cópia no caderno.

\section{Geração dos dados}

Os dados aqui utilizados foram gerados por meio de observação participante e não participante, coleta de documentos e artefatos, e registro em vídeo de atividades realizadas na sala de aula no período de Agosto a Novembro, totalizando 20 dias e 30 horas de gravação.

Tendo em vista que se tratava de uma pesquisa-ação, fiz uso de instrumentos qualitativos variados. Em um primeiro momento, 
questionários com os alunos e professora com o objetivo de buscar levantar dados sobre o uso diário de aparelhos de smartphones. Entrevistas com alunos e professora foram conduzidas a fim de realizar uma sondagem sobre o uso do aparelho de smartphone em sala de aula, promover reflexões e convidar os participantes a repensar suas ações a partir de uma perspectiva de rede.

\section{Análise de dados}

O conjunto completo dos dados ainda está sendo gerado e analisado, de modo que o que mostrarei neste artigo será uma pequena análise, baseada em uma das tarefas que criei, para ilustrar o uso da abordagem teórica escolhida, sem pretender tirar conclusões definitivas, uma vez que a pesquisa está em curso.

Nessa análise ilustrativa, focarei em parte de uma tarefa tentando identificar, em dois momentos consecutivos da análise, 1 . de que forma a tarefa afetou a rotina normal da aula no sentido de promover engajamento e, portanto, aprendizagem e 2. em que tipo de ator o aparelho celular se constituiu nessa atividade, em comparação com seu papel na rotina daquela sala de aula.

O problema apresentado pela tarefa era o produzir um vídeo utilizando os aparelhos celulares que refletissem a escola e a comunidade em que os alunos vivem. O vídeo deveria motivar os alunos a discutirem o tema: what's education for? Neste contexto, os alunos trabalharam a língua Inglesa por meio de músicas em inglês e da produção de frases que retratrassem a escola e a comunidade em que vivem.

Seguindo a proposta da TBL, iniciamos primeira etapa da tarefa com o pre-task com a professora introduzindo o tema what's education for? por meio de trechos dos vídeos: Another brick in the wall (Pink Floyd), Oasis (Emicida) e Pro Dia Nascer Feliz (documentário com direção de João Jardim), que apresentam a realidade escolar em contextos diversos. A professora questionou os alunos sobre o que eles, enquanto alunos do ensino médio prestes a sair da escola, tinham aprendido sobre educação e o que, nos vídeos, refletiria nisso.

$\mathrm{Na}$ etapa do ciclo de tarefas, a primeira atividade consistiu em fazer cenas do cotidiano (role plays) em que os alunos e a professora, com o apoio da pesquisadora, iniciaram uma discussão, ora em língua inglesa, ora em língua portuguesa - nos momentos em que os alunos não compreendiam claramente a tarefa - sobre o tema what would you do if you were (o que você faria se fosse) the student and the teacher (o aluno e o professor), no contexto dos vídeos apresentados. 
Os alunos inicialmente escreveram nos cadernos seus posicionamentos e usaram seus smartphones para traduzir as palavras e frases que não conseguiam formar em língua inglesa. A professora e a pesquisadora auxiliaram neste momento com a formação, correção e pronúncia de frases. Os alunos socializaram suas respostas em língua inglesa seguindo uma ordem elaborada pela professora. Nesta atividade, os alunos utilizaram o aparelho celular para consultar um dicionário online, ou seja, atrelou à translação um mediador externo, o dicionário, que serviu de elemento -estabilizador, evitando que o aluno se dispersasse da tarefa quando não sabia algo na língua inglesa que era necessário saber.

$\mathrm{Na}$ etapa de planejamento, os alunos, divididos em grupos, produziram um vídeoclipe em que retrataram a realidade da escola e da comunidade em que vivem. Os grupos escolheram uma música em língua inglesa e realizaram a montagem das imagens. Os vídeos foram produzidos com o aparelho celular por meio do aplicativo Triller $^{3}$. Neste caso, além de trazer para a aula os elementos musicais e videográficos que cumpriam o papel de representar a questão em debate por meio de outras linguagens que não a verbal, o aparelho também atuou como um montador/editor profissional de vídeo, por meio dos algoritmos acionados no aplicativo, permitindo aos alunos expressarem suas ideias videograficamente mesmo sem disporem do conhecimento técnico necessário para as operações mecânicas efetivadas, e, com isso, permitindo que os alunos atuassem, por um momento, como diretores/ criadores do texto audiovisual.

O passo seguinte foi o de mostrar o vídeo produzido pelos grupos a sala, ou seja, o resultado de uma das atividades da tarefa. Neste momento de socialização, o smartphone exibiu cenas que remetiam a sentimentos negativos, de privação e descaso, compiladas pelos alunos, cenas essas que chamaram a atenção da professora e da pequisadora. Um grupo em especial mostrou a escola como uma prisão. Podemos tomar a prisão, neste caso, como mais um mediador da rede constituída no antamento da tarefa, um elemento visual/narrativo que, pela vOz do celular, não a deles, diretamente, Ihes permitiuexpressar com franqueza como se sentiam em relação à escola, algo que, nas ocasiões anteriores, transparecia indiretamente apenas do seu comportamento, inclusive pelos usos que faziam do celular, naquele caso voltados para a evasão mental e emocional da sala de aula, mesmo estando presentes fisicamente. 
Mesmo que intermitentemente, já que houve momentos de dispersão e desinteresse, embora muito poucos, em comparação com o usual daquela turma, esses elementos permitiram fazer convergir interesses dos alunos, da professora e até mesmo os da pesquisadora, num fluxo de ações e significações que efetivamente se poderia chamar de aula. Posso inferir que isso é creditável, em grande parte, ao design da tarefa, um ator central da aula que trouxe consigo os elementos subjetivos, semióticos e didáticos ali articulados e, ao mesmo tempo, disciplinou o aparelho celular, proporcionou a ele assumir diferentes papéis em que suas próprias capacidades e intresses fossem atendidos em um arranjo produtivo de agencias humanas e não-humanas

Em um segundo momento da análise, focando no aparelho celular propriamente dito ainda durante a tarefa, houve, também, ocasiões em que o artefato ajudou a desmontar a rede e, portanto, fazer ruir o processo de aprendizagem. Esses momentos eram quando alguns alunos, ao se sentirem ociosos, desmotivados ou não interessados na aula - muitas vezes por estarem cansados do dia de trabalho, utilizavam o aparelho celular para ouvir músicas, entrar em redes sociais, conversar com amigos, jogar, etc., elementos que os desconectavam da aula se conectando, por meio do aparelho celular, a outras translações - soltando-se da rede da aula e agarrar em outras redes.

Reagindo a isso, isto é, por não ver os alunos se engajarem efetivamente em alguns exercícios (como o de trocarem mensagens em inglês) ao longo da execução da tarefa, a professora por algumas vezes -colocava a tecnologia em cheque, "ameaçando" voltar aos exercícios do livro didático e cópias da lousa, isto é, ao fazer a tarefa ruir, o celular também fazia a professora sentir-se menos professora, tornar-se um ator marginal, e, em resposta, ela cogitava de trazer esses outrs atores, capazes de fixar a atenção e canalizar a produção dos alunos no tempo e no espaço.

Por outro lado, pude observar que houve momentos de estabilidade no fluxo da aprendizagem proporcionados pelo aparelho celular, especialmente no que tange a filmagem, a montagem do vídeoclipe, e a discussão sobre como elaborar o videoclipe em sala de aula. Foi por meio do aparelho que os alunos conseguiram articular os atores que constituem sua realidade cotidiana e seus sentimentos a respeito da sala de aula, fazendo convergir vozes, metáforas e narrativas capturadas, modificadas e amalgamadas pelo aparelho.

Entendo que essa estabilidade se deveu, também, à postura adotada pela professora frente aos encontros reflexivos, e, consequentemente, 
à sua ação ao conduzir, de forma diferente das aulas e das atividades usuais, a tarefa por nós desenhada. Diferentemente do passado, quando, aparentando estar no controle, o que fazia era "manter aparências", ela conseguiu, aliando-se à tarefa, permitir que a discussão dos alunos fosse aberta e fluída. Essa transformação do ator "professor" repercutiu na forma de agir dos alunos, que vislumbraram, ao menos no espaço daquelas aulas, uma maneira de trazer a escola, enquanto ator, para o fluxo de sentidos e experiências que constituem suas vidas, mesmo que para criticá-la, o que é qualitativamente muito melhor do que estar nela em atitude totalmente desengajada, como costumava ser.

Notadamente, o desenho da tarefa e o potencial do aparelho celular, juntos, tiveram um papel fundamental para mudar, ainda que momentaneamente, o cenário que eu havia encontrado na aula anteriormente. Mas é importante notar que nem um nem outro "causou" a mudança. Na verdade, o que fizeram foi oferecer todo um conjunto novo de possibilidades de conexão entre a língua inglesa, a sala de aula e a vida dos alunos e da professora, conexões essas que, quando efetivadas, foram por vezes produtivas, por outras nem tanto, em termos do processo de ensino-aprendizagem. Dito de outra forma, os desafios do desengajamento, do autoritarismo, da sensação de aprisionamento etc. aparecem mesmo que de uma forma diferente da chamada aula "convencional", porque trata-se da mesma instituição, da mesma comunidade, dos mesmos corpos e mentes: se essa experiencia, urdida no âmbito de uma pesquisa-ação, vai ou não se estabelecer como uma nova prática de sala de aula é algo que vai depender, como sempre, de como os atores que lá estão, e que para lá possam se trazidos, vão se comportar quando entrelaçados, ou seja, de que identidades assumirão a professora, os alunos, o celular e a tarefa quando as suas agências se puserem a circular.

Nesse sentido, também, faz-se necessário de ressaltar o meu papel na realização da tarefa vis a vis o fato de que, ao fazer essa pesquisaação, tenho minha própria translação em curso, de modo que fui também um ator que colaborou, assim como o celular e a tarefa, para que as aulas e o processo de ensino-aprendizagem se estabelecessem, mesmo que temporariamente. Como professora que sou, ajudei a professora e os alunos a não deixarem a translação desmoronar de várias formas: auxiliando no desenho da tarefa e no uso das tecnologias, participando das aulas e monitorando o trabalho dos alunos e assim por diante. Como pesquisadora, ajudei não apenas a professora e os alunos, como a mim mesma, não deixando que, por iniciativa da professora, tudo voltasse 
a ser na base do livro didático e da cópia da lousa, e, logo, do celular para ouvir música ou tirar foto da matéria. Se assim não fosse, como poderia ter observado as sucessivas transformações nos papéis dos atores, e os elementos mediadores trazidos de fora para permitir que a relação entre a professora, os alunos e a língua inglesa fluísse melhor? Enquanto pesquisadora, é preciso que note isso, na medida em que, na perspectiva da TAR, o pesquisador é parte da rede que ele descreve, e deve levar isso em conta. A consequência dessa observação, é claro, está em que esses resultados preliminares não devam sugerir ao leitor que um bom conjunto de tarefas e um bom número de smarphones em sala de aula serão capazes de configurar a rede "sala de aula" num sentido produtivo se o professor e os alunos não forem apoiados, como fiz, para se responsabilizarem pela realidade que estão tecendo quando participam do que chamamos de "aula".

\section{CONSIDERAÇÕES FINAIS}

A lei permite o uso pedagógico do aparelho celular em sala de aula. No entanto, falta uma abordagem clara de qual a definição do uso pedagógico a se aplicar, por exemplo, no ensino de língua inglesa e, por outro lado, de até que ponto é válida, hoje, uma pedagogia que multile o artefato em suas possibilidades de ação e mediação, não contribuindo para a inovação que ele pode proporcionar. Neste artigo busquei ilustrar o potencial de uma abordagem de uso do celular por meio da Aprendizagem Baseada em Tarefas que explorem os seus diferentes potenciais, os quais podem ser identificados de forma relacional, contemplando-se os demais atores humanos e não-humanos envolvidos no ensino-aprendizagem em sala de aula, por meio da Teoria Ator-Rede.

Evidentemente, com esses achados preliminares não se pode afirmar o que é, de forma exaustiva, o uso pedagógico inovador do smartphone no ensino-aprendizagme de inglês. Todavia, os dados preliminares aqui apresentados sugerem que uma tarefa bem desenhada, no sentido de engajar o smartphone, os alunos, o professor, e as representações de mundo por eles compartilhadas, ou disputadas, numa rede fluida e produtiva pode, de fato, fazer toda a diferença.

Traçando uma comparação com o que era a aula antes da pesquisa, surgiu, de certa forma, na professora, um entendimento novo da situação de ensino-aprendizagem de língua inglesa e uma capacidade maior de mudar o estado de sua aula que saiu da tecnologia da lousa, giz, caderno, caneta etc. , utilizando a tecnologia do aparelho de celular do tipo 
smartphone e suas funcionalidades. Já os alunos, após da discussão e da elaboração do vídeoclipe, apresentaram uma postura de certa maneira crítica sobre o tema o sentido e a finalidade de sua escolarização.

Talvez o mais importante, para que essa rede se instale e seja sustentável, seja despertar nos atores humanos a consciência de que a aula, a aprendizagem, a capacidade de ensinar e aprender não são caixas pretas que se tem ou se usa, mas configurações e mobilizações de elementos para causar efeitos.

Ao trabalhar nos moldes da TAR, trabalhamos com a noção de que toda rede é um ator que participa de outra rede e que, portanto, o que acontece em (sala de) aula é um ator que constitui o que acontece na escola como um todo: desde a comunidade até no âmbito da educação geral.

Logo, encontrar caminhos para que o aparelho celular se integre efetivamente na aula, se repetido em todas as aulas, em todas as escolas, em todas as comunidades pode fazer considerável diferença - fato que podemos constatar observando outras esferas sociais como a política, o entretenimento, o comércio, etc., em que o smartphone foi apropriado em todo o seu potencial.

Obviamente, nesses outros espaços, os compromissos são com outros fatores que não necessariamente a aprendizagem, e, por este motivo, é indispensável entender as tarefas, pois estas podem estruturar a apropriação rede mantendo o rumo da aprendizagem. Por essa razão é importante estudar a tarefa como um ator tão, ou mais importante, do que o aparelho celular.

\section{REFERÊNCIAS}

BUZATO, M. E. K. Cultura digital e apropriação ascendente: apontamentos para uma educação 2.0. Educação em revista, v. 26, n.3, 2010, p. 283-303.

COCHRANE, T., AND R. BATEMAN. Smartphones give you wings: Pedagogical affordances of mobile Web 2.0. Australasian Journal of Educational Technology 26, no. 1. p. 1-14. 2010.

COLL, C., e MONERO, C. (Orgs.). Psicologia da Educação Virtual: aprender e ensinar com as tecnologias da informação e da comunicação. (N. Freitas, Trad.; M. da R. Silva, Rev.). Porto Alegre: Artmed, 365 p. 2008.

ELLIOTT, J. Action Research for Educational Change. Milton Keynes e Philadelphia: Open University Press. 1991.

FENWICK, T., AND R. EDWARDS. Actor-network theory in education. London: Routlege. 2010. 
FOX, S. An actor-network critique of community in higher education: Implications for networked learning. Studies in Higher Education 30, no. 1. p. 95-110. 2005.

Koole, M. Framework for the rational analysis of mobile education (FRAME): A model for evaluating mobile learning devices. Thesis, Centre for Distance Education, Athabasca University. 2006.

KUKULSKA-HULME, A. Re-skilling language learners for a mobile world. Monterey, CA: The International Research Foundation for English Language Education. 2013. Disponível em http://www.tirfonline.org/english-in-the-workforce/mobile-assisted-languagelearning/ .

LATOUR. Reassembling the social: An introduction to actor-network theory. Oxford: Oxford University Press. 2005.

LAW, J; HASSARD, D. Systemic Practice and Action Research 5, no. 4. p. 379-93. 1999.

LEE, N., BROWN, S. Otherness and the Actor Network. American Behavioural Scientist, 37(6), p. 772-790. 1994.

MOHAMMAD. H; FAYYOUMI A; ALSHATHRY. O. Do We Have to Prohibit the Use of Mobile Phones in Classrooms? SHORT PAPER. Al Imam Mohammad Ibn Saud Islamic University (IMSIU), Riyadh, Saudi Arabia. Disponível em http://dx.doi.org/10.3991/ijim. v9i2.4394. 2015. Acesso em 06.06.2016

NESPOR, J. Knowledge in motion: Space, time and curriculum in undergraduate physics and management. Philadelphia, PA: Routledge Falmer. 1994.

Networks and Contexts of Reform, Journal of Educational Change, 3. p. 365-382. 2002.

NUNAN. D. Research Methods in Language Learning. Cambridge: CUP. 1992.

. Action Research in the language classroom. In: Richards, J. C. e D. Nunan (orgs). Second Language Teacher Education. Cambridge, CUP.2002.

Task based language teaching. Cambridge: Cambridge University

Press. 2004.

POLL, HARRIS. Pearson Student Mobile Device Survey: College Students May 16, 2014. ROTH, W.-M. AND MCGINN, M.K. Science in schools and everywhere else: what science educators should know about science and technology studies, Studies in Science Education, vol. 29, no. 1. p. 1-43. 2007.

SHARPLES, M., J. TAYLOR, AND G. VAVOULA. Towards a theory of mobile learning. Paper presented at mLearn 2005, October 25-28, in Cape Town, South Africa. 2005. A theory of learning for the mobile age. 
In The SAGE handbook of e-learning research, ed. R. Andrews and C. Haythornthwaite, 221-47. London: Sage Publications. 2007.

SHARPLES, M., M. MILRAD, I. ARNEDILLO SANCHEZ, AND G. VAVOULA. Mobile learning: Small devices, Big issues. In Technology enhanced learning: Principles and products, ed. S. Balacheff, S. Ludvigsen, T. de Long, A. Lazonder, and S. Barnes, 233-49. Heidelberg: Springer. 2009.

STOCKWELL G; LIU, YI CHUN. Engaging in mobile phone-based activities for learning vocabulary: An investigation in Japan and Taiwan. CALICO. Vol 32.2 pp. 299-322. 2015.

STOCKWELL, G., HUBBARD, P. Some emerging principles for mobile-assisted language learning. Monterey, CA: The International Research Foundation for English Language Education. 2013. Disponível em http://www.tirfonline.org/english-in-the-workforce/ mobile-assisted-language-learning. Acesso em: 06 jun. 2016.

STOLLER-SCHAI, DANIEL. Mobile Learning Beyond Tablets and Smartphones: How Mobile and Networked Devices Enable New Mobile Learning Scenarios in Y.A. Zhang (ed.), Handbook of Mobile Teaching and Learning, DOI 10.1007/978-3-642-541469_71. \#Springer-Verlag Berlin Heidelberg. 2015.

Mobile learning for languages: Can the past speak to the future? Monterey,

CA: The International Research Foundation for English Language Education. 2013. Disponível em http://www.tirfonline.org/english-in-the-workforce/mobile-assistedlanguage-learning/. Acesso em: 08 jun. 2016.

VYGOTSKY, L. S. Mind in society. MIT Press, Cambridge, MA. 1978.

Pensamento e linguagem. São Paulo: Martins Fontes. (1934) 1994.

A Formação social da mente. São Paulo: Martins Fontes, (1930) 2000.

WILLIS, D. A Framework for Task-Based Learning. London: Longman. 1996.

WILLIS, D., e WILLIS, J. Doing task based teaching. Oxford: Oxford University Press. 2007. 